\title{
Center for Electronics and Electrical Engineering
}
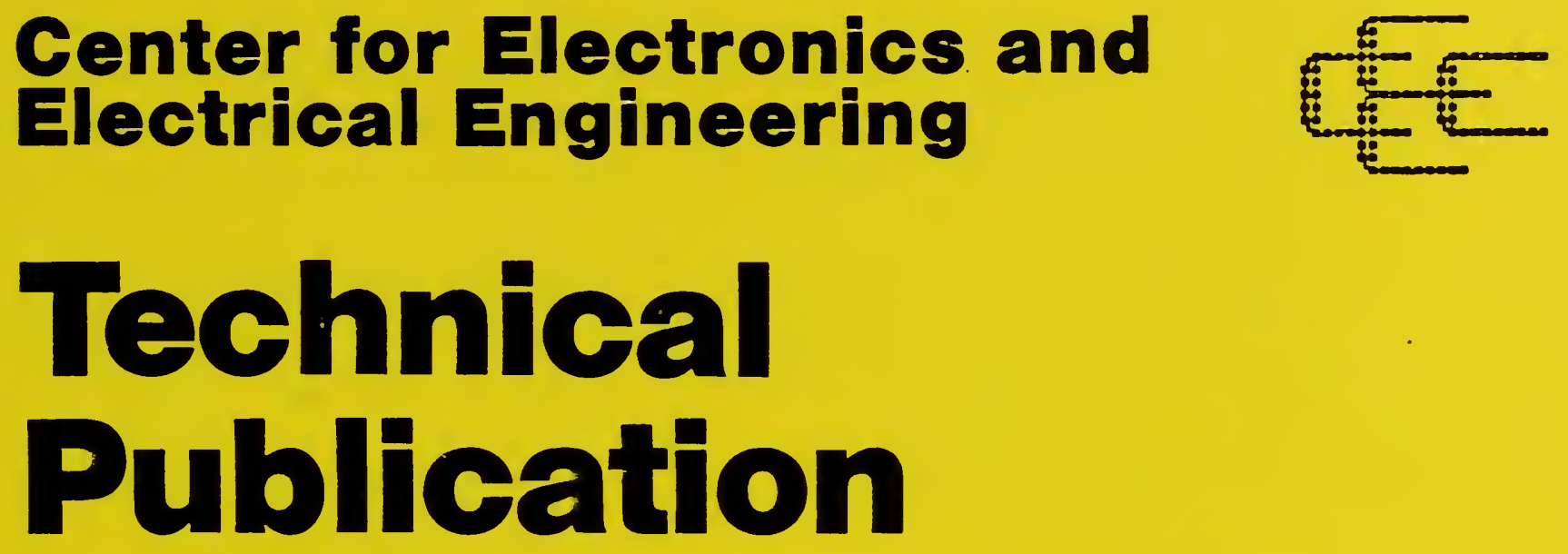

Announcements

\section{Covering Center Programs,} October to December 1986, with 1987 CEEE Events Calendar

August 1987

U.S. Department of Commerce

National Bureau of Standards

National Engineering Laboratory

Gaithersburg, Maryland 20899

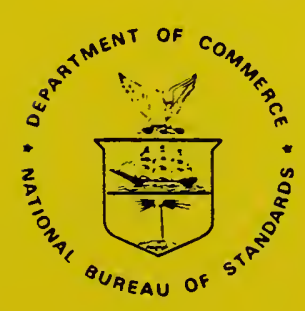


This is the eleventh issue of a quarterly publication providing information on the technical work of the National Bureau of Standards Center for Electronics and Electrical Engineering. This issue of the CEEE Technical Publication Announcements covers the fourth quarter of calendar year 1986.

Organization of Bulletin: This issue contains citations and abstracts for Center papers published in the quarter. Entries are arranged by technical topic as identified in the table of contents and alphabetically by first author within each topic. Following each abstract is the name and telephone number of the individual to contact for more information on the topic (usually the first author). This issue also includes a calendar of Center conferences and workshops planned for calendar year 1987, some preliminary events for 1988, and a list of sponsors of the work.

Center for Electronics and Electrical Engineering: Center programs provide national reference standards, measurement methods, supporting theory and data, and traceability to national standards.

The metrological products of these programs aid economic growth by promoting equity and etficiency in the marketplace, by removing metrological barriers to improved productivity and innovation, by increasing U.S. competitiveness in international markets through facilitation of compliance with international agreements, and by providing technical bases for the development of voluntary standards for domestic and international trade. These metrological products also aid in the development of rational regulatory policy and promote efficient functioning of technical programs of the Government.

The work of the Center is divided into two major programs: the Semiconductor Technology program, carried out by the Semiconductor Electronics Division in Gaithersburg, MU, and the Signals and Systems Metrology Program, carried out by the Electrosystems Division in Gaithersburg and the Electromagnetic Fields and Electromagnetic lecnnology Divisions in Boulder, $\mathrm{CO}$. See the table of contents on the opposite page for identification of the topics covered by each program, as represented in this issue. Key contacts in the center are given on the back cover; readers are encouraged to contact any of these individuals for further information.

Center sponsors: The Center Programs are sponsored by the National Bureau of Standards and a number of other organizations, in both the Federal and private sectors; tnese are identified on page 13.

Note on Publication Lists: Guides to earlier as well as recent work are the publication lists covering the work of each division. These lists are revised and reissued on an approximately annual basis and are available from the originating division. The current set is identified in the Additional Information section, page 10. 


\section{TABLE OF CONTENTS}

INTRODUCTION

SEMICONDUCTOR TECHNOLOGY PROGRAM

Dimensional Metrology

Packaging

Device Physics and Modeling

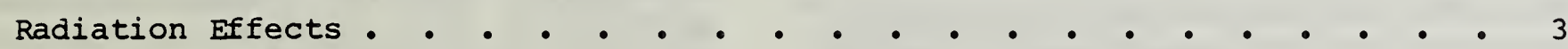

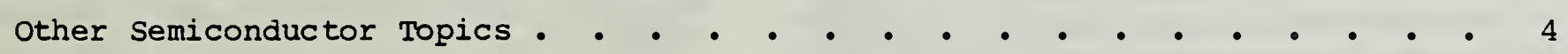

FAST SIGNAL ACQUISITION, PROCESSING, \& TRANSMISSION • • • • • • • •

Waveform Metrology • • • • • • • • • • • • • • • • • • 5

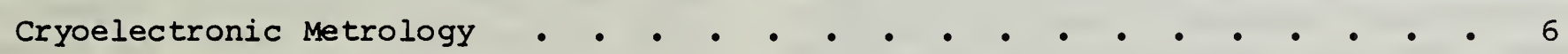

Laser Metrology • • • • • • • • • • • • • • • • • • • 6

Microwave and Millimeter-Wave Metrology • • • . . . . . • . . 6

Optical Fiber Metrology • • • • • • • • • • • • • • • • • 6

ELECTRICAL SYSTEMS • • • • • • • • • • • • • • • • • •

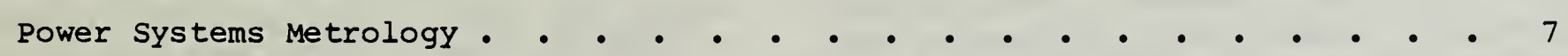

Superconductors • • • • • • • • • • • • • • • • • • • 8

ELECTROMAGNETIC INTERFERENCE • • • • • • • • • • • • • • • •

Radiated Electromagnetic Interference • • • • • • • • • • • • 9

Conducted Electromagnetic Interference • • • • • • • • • • • • 9

ADDITIONAL INFORMATION • 1987 CEEE CALENDAR • • • • • • • • • • • • • • • • • • • • • SPONSOR LIST • • • • • • • • • • • • • • • • • • • • KEY CONTACTS IN CENTER, CENTER ORGANIZATION • • • • • • • • • • back cover 


\section{SEMICONDUCTOR TECHNOLOGY}

\section{Dimensional Metrology}

Postek, M.T., and JoY, D.C., Microelectronics Dimensional Metrology in the Scanning Electron Microscope, Part I, Solid State Technology, Vol. 29, No. 11, pp. 145-150 (November 1986); Part II, Solid State Technology, Vol. 29, No. 12, pp. 77-85 (December 1986) [also to appear in NBS Journal of Research].

The Increasing integration of microelectronics into the suomicrometer region for very-large-scale and very-high-speed integrated-circuit applications necessitates the examination of these structures both for linewidth measurement and for derect inspection by systems other than the optical microscope. The low beam-voltage scanning electron microscope (SEM) has been employed recently in this work due to. its potentially high spatial resolution and to its large depth of field. The applications of the scanning electron microscope to microelectronics inspection and metrology are discussed in light of the present instrument specifications and capabilities, and the processing controls required for submicrometer processing are examined. The discussion includes effects of the electron beam/sample interaction and its modeling with the Monte Carlo technique. Various sources of error in SEM metrology are also examined. In conclusion, the prospect of automated wafer inspection and progress in establishing SEM measurement standards are outlined.

[Contact: Mi chael T. Postek, (301)

975-2299]

\section{$\underline{\text { Packaging }}$}

Oettinger, F.F., Thermal Characterization of Integrated Circuits -- A Tutorial, Proceedings of semiconductor Thermal and Temperature Measurement Symposium, Scottsdale, Arizona, December 9-11, 1986, pp. T2-1 to $\mathrm{T} 2-4$ (1986).
This tutorial deals with the practicalities of the thermal characterization of integrated circuit devices and packages, utilizing both computational and experimental techniques.

[Contact: Frank F. Oettinger, (301)

975-2054]

Device Physics and Modeling

Bennett, H.S., High Dopant and Carrier Concentration Effects in Gallium Arsenide: Band structure \& Effective Intrinsic Carrier Concentrations, Journal of Applied Physics, Vol. 60, No. 8, pp. 2866-2874 (15 October 1986)。

The quality and reliability of predictions from numerical simulations of GaAs/AIGaAs devices, such as heterojunction bipolar transistors, depend on input parameters. These parameters include the variations with doping and carrier concentrations of the valence and conduction band edges and of the effective intrinsic carrier concentrations for heavily doped p-type and n-type gallium arsenide. The Klauder self-energy method is used to calculate the effects of the one-body interactions among the dopant ions and the carriers in heavily doped gallium arsenide at 300 K. The many-body interactions of exchange and correlation are estimated by interpreting optical absorption measurements and by calculations based on degenerate theory . When densities exceed $10^{19} \mathrm{~cm}^{3}$ in p-type and $10^{17} \mathrm{~cm}^{-3}$ in n-type GaAs, one-body and many-body terms become of the same order of magnitude and should be included in calculations of band structure changes and of properties which depend on the density of states, such as carrier transport and effective intrinsic carrier concentrations.

[Contact: Herbert S. Bennett, (301) 975-2079]

Bennett, H.S., Modeling Silicon Enitters for VLSI Transistors, Proceedings of the Workshop on New Developments in the Physics of Homojunctions 
Device Physics and Modeling, cont'd.

and Heterojunctions, Leuven, Belgium, May 28-29, 1986, unpaged (December 1986).

The accuracy and reliability of predictions from numerical simulations of advanced bipolar transistors for verylarge-scale integration (VLSI) applications depend on model parameters. These parameters include the variations with doping and carrier concentrations in both n-type and p-type silicon of 1) the valence and conduction band edges, 2) the effective intrinsic carrier concentrations, 3) the minority carrier mobilities, and 4) the minority carrier lifetimes. This paper reviews recent advances in device physics for modeling the emltters of bipolar transistors with suomlcrometer dimensions and high concentrations of dopant ions and carriers.

[Contact: Herbert S. Bennett, (301)

975-2079]

Lowney, J.R., Impurity Bands and Band Tailing in n-Type GaAs, Journal of Applied Physics, Vol. 60, No. 8, pp. 2854-2859 (15 October 1986).

The densities of states of the valence and conduction bands of n-type GaAs have been calculated for a donor density of $10^{17} \mathrm{~cm}^{3}$ at $300 \mathrm{~K}$ and $20 \mathrm{~K}$. Both the donor-carrier and carrier-carrier interactions have been included. Band tails appear on both bands and the energy gap is narrowed. Calculations were also performed tor a donor density of $10^{15}$ $\mathrm{cm}^{-3}$. The results show the formation of an impurity band at $20 \mathrm{~K}$, whereas a band tail exists at $300 \mathrm{~K}$.

[Contact: Jeremiah R. Lowney, (301)

975-2048]

Radiation Effects

Hefner, A.R., Blackburn, D.L., and Galloway, K. F., The Effect of Neutrons on the Characteristics of the Insulated Gate Bipolar Transistor (IGBT), IEEE Transactions on Nuclear Science, Vol.
NS-33, No. 6, pp. 1428-1434 (December 1986) .

The effects of neutrons on the operating characteristics of Insulated Gate Bipolar Transistors (IGBT) are described. Experimental results are presented for devices that have been irradiated up to a fluence of $10^{13}$ neutrons $/ \mathrm{cm}^{2}$, and an analytical model is presented which explains the observed effects. It is found that with increasing neutron fluence, the on-state voltage increases, the switching time decreases, and the saturation current decreases. For the range of fluences studied, the observed effects result from a reduction in minority carrier lifetime in the IGBT and not from changes in the effective dopant density. The effects of neutrons on the IGBT are compared with their known effects on power metal oxide-semiconductor field-effect transistors (MOSFETs), and it is shown that the IGBT characteristics begin to degrade at a fluence that is an order of magnitude less than the fluence at which the power MOSFET begins to degrade. At high fluences, the IGBT takes on the characteristics of a power MOSFET.

[Contact: Allen R. Hefner, (301)

975-2071]

Pugh, R.D., Johnston, A.H., and Galloway, K.F., Characteristics of the Breakdown Voltage of Power MOSFFTs After Total Dose Irradiation, IEEE Transactions on Nuclear Science, Vol. NS-33, No. 6, pp. 1460-1464 (December 1986).

The effects of total dose irradiation on the breakdown voltage of p-channel power metal oxide-semiconductor field-effect transistors (MOSFETs) are examined. Although breakdown voltage for p-channel devices increased at higher dose levels, as expected, some devices exhibited an initial decrease in breakdown at very low levels of total dose. The interaction of ionizing radiation effects with the junction termination methods designed to increase the voltage at which breakdown occurs is analyzed. 
Radiation Effects, cont'd.

[Contact: Thomas J. Russe11, (301)

975-2973]

Russel1, T.J., Bennett, H.S., Gaitan, M., Suehle, J.S., and Roitman, P., Correlation Between CMOS Transistor and Capacitor Measurements of Interface Trap Spectra, IEEE Transactions on Nuclear Science, Vol. NS-33, No. 6, pp. 1228-1233 (December 1986).

The radiation-induced change in the energy spectra of $\mathrm{SiO}_{2}-\mathrm{Si}$ interface traps as determined using 1) the chargepumping and weak-inversion techniques on compound metal oxide-semiconductor (CMOS) transistors and 2) using the quasiostatic capacitance voltage and detailed model techniques on CMOS capacitors are compared. The interface trap spectra determined from these measurements are in good quantitative agreement over most of the band gap for the range of densities of traps approximately $10^{10}$ to $10^{12} \mathrm{~cm}^{-1} \mathrm{ev}^{-1}$.

[Contact: Thomas J. Russell, (301)

975-2073]

Singh, G., Galloway, K. F., and Russell, T.J., Radiation-Induced Interface Traps in Power MOSFBIs, IEEE Transactions on Nuclear Science, Vol. NS-33, No. 6, pp. 1454-1459 (December 1986).

Methods for estimating values of radiation-induced interface trapped charge from the current-voltage (I-V) characteristics of metal oxide-semiconductor field-effect transistors (MOSFETs) are described and applied to commercially available power MOSFETs. The power MOSFErS show severe degradation on radiation exposure with the effects of positive oxide trapped charge dominating; however, interface trap buildup is significant. The results are compared to experimental measurements available on other technologies.

[Contact: Thomas J. Russell, (301)

975-2073]

Other Semiconductor Topics
Larrabee, R.D., and Bell, M.I., Nondestructive Bvaluation Activities in the Semiconductor Materials and Processes Division, NBSIR 86-3495 (December 1986).

This is the first of an anticipated yearly report of the nondestructive evaluation and measurement development activities currently in progress. in the Semiconductor Materials and processes Division of the National Bureau of Standards. Present activities include production and certification of standard reference materials for resistivity and optical measurement of linewidths on transparent photomasks; orchestrating round robins for ellipsometric layer thickness, deep-level characterization, and spreading resistance; developing new techniques for optical deep-level spectroscopy, profiling resistivity, and recombination lifetime in ingots of very high resistivity silicon; for measuring oxygen in silicon by infrared absorption; for characterizing compound semiconductor wafers by optical and $x-r a y$ techniques; and for extending the photomask linewidth work to thicker lines on silicon substrates.

[Contact: Robert D. Larrabee, (301)

975-2298]

Novotny, D.B., Measurement of the Separation Distance in contact and Proximity Lithography, Journal of the Electrochemical Society, Vol. 133, pp. 2600-2605 (December 1986).

A method is presented for measuring the separation distance between the substrate surface and the mask surface in contact and proximity optical lithography. This method utilizes the analysis of the Fresnel diffraction pattern produced by a slit aperture in the mask and physically replicated in the photoresist. From the analysis, the image distance producing the observed Fresnel diffraction pattern is obtained and is used to calculate the separation distance. The conditions for the application of this method are presented and an easy method for computer-generation of 


\section{Other Semiconductor Topics, cont'd.}

the Fresnel diffraction patterns is described. A simplified method for estimating the separation distance from the number of diffraction pattern peaks and valleys is also given. Results are presented showing that a finite separation distance may exist in hard "contact" lithography and that this measurement method is applicable from distances from near zero to 20 or more micrometers.

[Contact: Donald B. Novotny, (301)

975-2699]

Stern, E.A., Ma, Y. and Bouldin, C.E. Answer to Comment by M.A. Marcus Concerning "Local Structure at Mn Sites in Icosahedral Min-Al Quasicrystals", Physical Review Letters, Vol. 57, No. 13, p. 1659 (September 29, 1986).

A response is given to M.A. Marcus who raised questions about the data analysis leading to conclusions that EXAFS data of Stern et al. support a model involving two $M n$ sites, one of which is like that in $\left(x-A_{6} \mathrm{Mn}\right.$. The response showed that the results are consistent with the data and analysis presented in the paper.

[Contact: Charles E. Bouldin, (301)

975-2046]

Wunder, S.L., Bell, M.I., and Zerbi, G., Band Broadening of $\mathrm{CH}_{2}$ Vibrations in the Raman Spectra of Polymethylene Chains, Journal of Chemical Physics, Vol. 85, No. 7, pp. 3827-3839 (1 October 1986).

The isotropic and anisotropic linewidths of methylene viorations in a homologous series of alkanes of increasing chain length have been measured in the liquid state as a function of temperature. The bandwidths of the $\mathrm{CH}_{2}$ symmetric stretching modes, which are in Fermi resonance with overtones of the $\mathrm{CH}_{2}$ bending viorations, are temperature insensitive over a $200-\mathrm{K}$ interval, explained in terms of a vibrational dephasing mechanism (inhomogeneous broad- ening) for these modes. In contrast, for the bending and antisymmetric vibrations, significant band broadening occurs over this same temperature interval. In addition, for these modes, both the absolute value of the bandwidth and the relative rate of increase of the bandwidth with increasing temperature decrease with increasing chain length. These observations are consistent with a reorientational broadening mechanism as the principal bandwidth contribution for these vibrations. Hindered end-over-end rotation of the molecules, which contributes to the band broadening for very low molecular weight alkanes, rapidly becomes too slow to be observable on the time scale of the Raman experiment for the higher molecular weight alkanes and polyethylene. For longer chain lengths, torsional backbone motions coupled to the high frequency antisymmetric stretching modes can account for the breadth of the bands.

[Contact: Michael I. Bell, (301) 9752081]

FAST SIGRAL ACQUISITION, PROCESSING, AND TRANSYISSION

Waveform Metrology

Kanada, T., and Franzen, D.L., Optical Waveform Measurement by optical Sampling with a Mode-Locked Laser Diode, Optics Letters, Vol. 11, No. 1, pp. 4-6 (January 1986).

Optical pulses from a GaAlAs laser diode directly modulated at a frequency $f_{0}$ (971 MHz) are mixed in a $\mathrm{LiIO}_{3}$ crystal with optical sampling pulses at a frequency of $f_{0}-10 \mathrm{~Hz}$ from a mode-locked GaAlAs laser diode. The optical signal obtained by sum-frequency mixing in the crystal is observed with a photomultiplier and an oscilloscope. The original pulse waveform is reproduced clearly with a temporal resolution equal to the mode-locked laser-diode pulse width and at a repetition frequency of $10 \mathrm{~Hz}$. Similar results are obtained with InGaAsP laser diodes at a wavelength of $1.3 \mu \mathrm{m}$. 
Waveform Metrology, cont'd.

[Contact: Douglas L. Franzen, (303)

$497-3346$ or -5342$]$

\section{Cryoelectronic Metrology}

MCDonald, D.G., Hodeling a VoltageLocked Josephson Junction Array Amplifier: Gain, Input Impedance, and Bandwidth, Journal of Applied Physics, Vol. 60, No. 9, pp. 3247-3257 (November 1, 1986).

Previously published experimental results are used to deduce an equivalent circuit tor this amplifier, based on the shunted junction model. It is found that the very small inductances of the junction shunt resistors play an important role in determining the shape of the current-voltage curves in the voltage-locked region. Once the circuit is determined using the shunted junction model, a combination of an approximation method (the method of slowing varying amplituaes) and the shunted junction model is used to approximately maximize the power gain of the circuit. The maximum gain achieved in these simulations of the two-junction amplifier is 11.3. This gain occurred with a negative resistance input impedance of $-0.41 R$ and a signal source impedance of $0.167 R$, where $R$ is the junction shunt resistance. It is estimated that the bandwidth of this amplifier is about $1 \mathrm{GHz}$.

[Contact: Lonald G. McDonald, ( 303 )

497-5113]

\section{Laser Metrology}

Johnson, E.G., Direct Measurement of the Spatial sodes of a Laser pulse Theory, Journal of Applied Optics, Vol. 25, No. 17, pp. 2967-2975 (September 1986).

We make an electric-field measuring apparatus by using optical processing, tapered optical fibers, and a pair of detectors at the end of each optical riber. Using an appropriate computer- generated hologram ( $\mathrm{CGH}$ ), we show it is possible to discriminate among a set of orthonormal modes used to represent the spatial features of the electric field with a signal-to-noise ratio of at least 100 to 1. The tapered fiber is a mode filter that is used in the transform plane of the CGH. This fiber allows precise determination of the strength of each of the orthonormal modes being used as the spatial basis of the electric field before the optical processing.

[Contact: Eric G. Johnson, (303) 497-3234]

Microwave and Millimeter-Wave Metrology

Hoer, C.A., On-Line Accuracy Assessment for the Dual Six-Port ANA: Treatment of systematic Errors, CPEM (Conference in Precision Electrical Measurements) Digest, NBS Gaithersburg, MD, June 23-27, 1986, R.F. Dziuba, ed., pp. 238-239 [abbreviated version]; [complete paper to be published in a special issue of IEEE Transactions on Instrumentation and Measurement].

Expressions are derived for calculating systematic errors in dual six-port or four-port measurements of reflection coefficient and scattering parameters due to imperfections in the transmission line standard used to calibrate the system. A new mathematical model for a four-port reflectometer makes it easier to visualize and analyze these errors. [Contact: cletus A. Hoer, (303) 497-3703]

\section{Optical Fiber Metrology}

Kanda, T., and Franzen, D.L., SingleMode Fiber Dispersion Measurements Using Optical sampling with a ModeLocked Iaser Diode, Optical Letters, Vol. 11, pp. 330-332 (May 1986).

Pulses from a wavelength-tunable, modelocked laser diode were measured after $21 \mathrm{~km}$ of single-mode fiber propagation by optical sampling with another modelocked laser diode; a resolution of 0.1 $\mathrm{ps} /(\mathrm{nm} \cdot \mathrm{km})$ is achieved in this chromatic 
Optical Fiber Metrology, cont'd.

dispersion measurement. In another related experiment, 78-ps-duration pulses from an ordinary, multilongitudinal-mode laser diode are clearly displayed by optical sampling after $36 \mathrm{~km}$ of riber propagation. System bandwidth increases to approximately $500 \mathrm{GHz} \mathrm{km}$ as the laser-diode wavelength is temperature tuned through the zero-dispersion region.

[Contact: Douglas L. Franzen, (303) 497-3346 or -5342]

Yang, S., and Gallawa, R.L., Fiber Bandwidth Measurement Using Pulse Spectrum Analysis, Applied Optics, vol. 25, No. 7, pp. 1069-1071 (April 1986).

The pulse spectrum analysis method (PSA) of measuring fiber bandwidth has been suggested as an alternative to the frequency- and time-domain methods, but there is a paucity of information on the technique and very little data. In fact, we know of no prior measurement comparisons between the PSA method and frequency- and time-domain methods. This paper gives results of an experiment which compared the three methods. The PSA method has the advantage of being very simple and gives results that are consistent with the other two methods. The International Electrotechnical Commission recommends the PSA method, but the Electronics Industries Association of the U.S.A. takes no position in this regard.

[Contact: Robert L. Gallawa, (303) 497-3761)]

\section{ELECTRICAL SYSTEMS}

\section{Power Systems Metrology}

Mehta, S.P., and Petersons, O., Calibration of Test systems for Measuring Poser Losses of Transformers, IEEE Transactions on Power Delivery, Vol. PWRD-1, No. 4, pp. 215-223 (October 1986).

Two years of development work by ASEA
Electric, under the auspices of the Industrial Research Associate Program of the National Bureau of Standards, has resulted in a verifiable method of determining overall accuracy of test systems used in tine measurement of transformer losses. This technical achievement is important to the industry because of the present trend towards lower power factors which makes loss measurements exceedingly difficult with desirable test system accuracy that is traceable. The technical details of this work are presented in NBS Technical Note 1204 (over 100-page document). The intent of this IEEE paper is to present the basic principles embodied in the Technical Note. A calibration system for accuracy verification and alignment of test systems is described. Me thodologies and data for evaluating accuracy of test systems are summarized. The details elaborated upon in this paper represent a way to determine the accuracy of the overall test system for measuring transformer losses as well as that of the principal components of such a system.

[Contact: Oskars Petersons, (301)

975-2400]

Van Brunt, R.J., and Sauers, I., Gas Phase Hydrolysis of $\mathrm{SOF}_{2}$ and $\mathrm{SOF}_{4}$ ' Journal of Chemical physics, Vol. $85^{\prime}$, No. 8, pp. 4377-4380 (October 15, $1986)$.

The rates for gas-phase hydrolysis of $\mathrm{SOF}_{2}$ (thionylfluoride) and $\mathrm{SOF}_{4}$ (thionyltetrafluoride) have been measured at a temperature of $298 \mathrm{~K}$. The second order rate constant for $\mathrm{SOF}_{2}$ hydrolysis in $\mathrm{SF}_{6}$ buffer gas was found to have the value $(1.2 \pm 0.3) \times 10^{-23} \mathrm{~cm}^{3} / \mathrm{s}$ which agrees with previous estimates of Sauers et al., but is three orders of magnitude lower than the value obtained by Ruegsegger et al. at $340 \mathrm{~K}$. The rate constant for $\mathrm{SOF}_{4}$ hydrolysis has not previously been measured, and its value in both $S_{6}$ and $N_{2}$ buffer gases was found here to be $(1.0 \pm 0.3) \times 10^{-21}$ $\mathrm{cm}^{3} / \mathrm{s}$.

[Contact: Richard J. Van Brunt, (301) 975-2425] 


\section{Superconductors}

Dragomirecky, M., Minervini, J.V., Ekin, J.W., Goldfarb, R.B., and Clark, A.F., Losses in a $\mathrm{Nb}-\mathrm{Ti}$ Superconductor as Functions of $A C$ Field Amplitude and $D C$ Transport Current, Proceedings of the 11 th International Cryogenic Engineering Conference - ICEC 11, Berlin, West Germany, April 22-25, 1986 (Butterworth \& Co. Itd., Publishers), pp. 746-750.

Hysteretic shielding losses and transport losses were measured in a multifilamentary $\mathrm{Nb}-\mathrm{Ti}$ superconducting coil as tunctions of transverse ac field amplitude ana dc transport current. The conductor was biased with a dc field. There was significant agreement with the predictions of Minervini ${ }^{8} \mathrm{~s}$ two-dimensional theoretical model.

[Contact: Jonn W. Ekin, (303)

$497-5448]$

\section{Ekin, J.W., High-Field Flux Pinning} and the strain scaling Law, proceedings of the International symposium on Flux Pinning and Electromagnetic Properties in superconductors, Fukuoka, Japan, November 11-15, 1985, pp. 267271.

The effects of strain on flux pinning in superconductors are discussed. Significant aifferences between the strain scaling law, temperature scaling law, and the flux-line-shearing model of Kramer are demonstrated. The strain scaling law is more general than current Ilux-pinning models, and as such, it may serve as a guide to future work on flux pinning theory. Flux-pinning measurements at fields up to $24 \mathrm{~T}$ have been made on a series of high-quality $\mathrm{Nb}_{3} \mathrm{Sn}$ samples with third (and fourth) element additions. The data show that the usual extrapolation procedures for determining the bulk-average upper critical field in $\mathrm{Nb}_{3} \mathrm{Sn}$ lead to signiticant errors when additives such as Ti, Ta, Ga, and hf are present.

[Contact: John W. Ekin, (303) 497-5448]

Fickett, F.R., and Capobianco, T.E.,
Relationships Between Mechanical and Magnetoelectric properties of OxygenFree Copper at $4 \mathrm{~K}$, Advances in Cryogenic Engineering (Materials), Vol. 32, (Plenum Press, New York, NY, 1986), pp. $421-427$.

Commercially pure, oxygen-free copper is the material of choice for nearly all superconductor stabilization. Straining relatively pure copper at $4 \mathrm{~K}$ can result in significant increases in the residual resistivity and, thus, a decreased ability of the copper to stabilize the superconductor. In this paper, we quantify the effect of strain on the resistivity and magnetoresistivity of a large number of oxygen-free coppers from various sources and in various tempers. In addition, the low-temperature stressstrain behavior of these materials and its correlation with room temperature data and the residual resistivity ratio prior to straining is discussed. An apparatus developed for mechanical properties testing of relatively small wire samples at low temperature is described.

[Contact: Frederick R. Fickett, (303) 497-3785]

Goldfarb, R.B., and Clark, A.F., AC Losses in Nb-Ti Measured by Magnetization and Complex susceptibility, Advances in Cryogenic Engineering (Materials), Vol. 32 (Plenum Press, New York, NY, 1986), pp. 779-786.

DC magnetization and complex ac susceptibility were measured at $4 \mathrm{~K}$ as functions of longitudinal dc field for a multifilamentary $\mathrm{Nb}-\mathrm{Ti}$ superconductor with no transport current. Minor hysteresis loops were obtained in the dc measurements. The full-penetration field $H_{p}$, a function of applied field $H$, was deduced directly for each minor loop. The values for $H_{p}$ were fit to the Kim-type equation, $\mathrm{H}_{\mathrm{p}}(\mathrm{H})=$ $\mathrm{H}_{\mathrm{p}}(\mathrm{O}) /\left(1+\mathrm{H} / \mathrm{H}_{\mathrm{k}}\right)$, where $\mathrm{H}_{\mathrm{p}}(\mathrm{O})$ and $\mathrm{H}_{\mathrm{k}}$ are constants. The minorhysteresis-loop areas gave losses that were in excellent agreement with Carr's theoretical critical-state equation, $w=$ 
Superconductors, cont'd.

$\left(4 \mu_{0} \mathrm{H}_{0} \mathrm{H}_{\mathrm{p}} / 3\right)\left(1-\mathrm{H}_{\mathrm{p}} / 2 \mathrm{H}_{0}\right)$, where $\mathrm{H}_{0}$ is the maximum applied field for each loop.

An expression was obtained for the ideal reversible differential susceptibility, Xrev $=\phi_{0} / 8 \pi \mu_{0}\left(\mathrm{H}-\mathrm{HCl}_{\mathrm{Cl}}\right) \lambda^{2}$, where $\psi_{0}$ is the flux quantum, $\mathrm{H}_{\mathrm{Cl}}$ is the lower critical tield, and $\lambda$ is the penetration depth. $\mathrm{H}_{\mathrm{Cl}}$ and $\lambda$ for the sample were deduced from the shape of the major hysteresis loop. Clem's theoretical expressions for the real $\left(X^{\prime}\right)$ and imaginary $(x ")$ components of ac susceptibility are functions of ac field amplitude $h, H_{p}$, and $X_{r e v}$ The predicted susceptibilities based on these expressions were in good agreement with measured curves of $\chi^{\prime}$ and $\chi^{\prime \prime}$ as functions of $h$ and $H$. The measured $\chi^{\prime}$ and $x$ " were independent of frequency up to $1 \mathrm{kHz}$, as expected when bulk hysteresis is the primary loss mechanism.

[Contact: Ronald B. Goldfarb, (303)

497-3650]

Goodrich, L.F., Dube, W.P., Pittman, E.S., and Clark, A.F., The Effect of Aspect Ratio on Critical current in Multifilamentary Superconductors, Advances in Cryogenic Engineering (Materials), Vol. 32 (Plenum Press, New York, NY, 1986), pp. 833-840.

Experimental data and discussion are presented on the critical current of straight superconductors as a function of the orientation of a perpendicular applied magnetic field. Commercial, multifilamentary $\mathrm{NbTi}$ and $\mathrm{Nb}_{3} \mathrm{Sn}$ samples were measured in a radial access magnet that allowed an arbitrary angle setting. The change in critical current was measured at different magnetic fields to scale the effect for use in a standard test method. For a NbTi sample, the critical current with the magnetic field parallel to the wider face of the conductor is higher than that with the perpenaicular orientation. The effect can be as high as $40 \%$ for a NbTi sample with an aspect ratio of 6 . The effect in $\mathrm{Nb}_{3} \mathrm{Sn}$ is opposite that in $\mathrm{NbTi}$. $\mathrm{A}$ discussion of the most likely cause of the effect, which accounts for the difference between $\mathrm{NbTi}$ and $\mathrm{Nb}_{3} \mathrm{Sn}$, is given.

[Contact: Loren F. Goodrich, (303)

497-3143]

\section{ELECTROMAGNETIC INTERFEREANCE}

\section{Radiated Electromagnetic Interference}

Randa, J., and Kanda, M., A Lattice Approach to Volumes Irradiated by Unknown Sources, NBS Technical Note 1303 (Oc tober 1986).

We suggest an approach to the characterization of electromagnetic environments irradiated by unknown sources. The approach is based on the numerical solution of Maxwell's equations subject to the constraints imposed by the measured values of the field at a small number of measurement points and by boundary conditions. A thorough examination is presented of two methods for the numerical solution. The examples attempted demonstrate the approach, but reveal that neither technique is fully successful. Possible future directions are sugges ted.

[A paper based on the contents of this Technical Note is scheduled for presentation at the seventh symposium and Technical Exhibition on EMC (Zurich, Switzerland, March 1987) under the title "A Lattice Approach to Environments Irradiated by Unknown Sources" and will appear in the proceedings of that symposium. A second paper based on this material has been submitted to the IEEE Transactions on Electromagnetic Compatibility with the title "A New Approach to Volumes Irradiated by Unknown Sources."] [Contact: James P. Randa, (303) 497-3150]

Conducted Electromagnetic Interference

Key, T.S., and Martzloff, F.D., A Consensus on Powering and Grounding Sensitive Electronic Equipment, In- 
Conducted EMI, cont'd.

dustry Applications Society Annual Meeting, Denver, Colorado, September 29-october 3, 1986, pp. 1-7.

As sensitive electronic processing systems proliferate in our facilities, so do power-related problems. Efforts to alleviate these problems have ranged from installing expensive power conditioning equipment to applying special grounding techniques not found in conventional safe grounding practice. Understanding of what is actually going on has been lacking. We find elaborate power systems, modified from basic practice to the extent of being unsafe, that continue to be plagued with poweringand grounding-related problems. Out of this chaos we are persuaded to study and understand the complexities of the problem and to begin developing good practices. This is the objective of the IEEE working Group on Powering and Grounding Sensitive Electronic Equipment, Standards Project P1100. We will introduce Project P1100, preview its scope and technical content and, most importantly, invite participation in this seriously needed consensus standard activity.

[Contact: Francis D. Martzloff, (301)

975-2409]

Martzloff, F.D., Surge Suppressors and Clamps, Proceedings of EMC EXPO 86, International Conference on Electromagnetic Compatibility, Washington, DC, June 16-19, 1986, pp. E01.1-E01.7.

The paper presents a review of technologies developed for surge suppressor devices used in electronic circuits. Three generic types are described: crowbars, varistors, and avalanche diodes. The significant differences in their performance characteristics are pointed out, together with guidance on proper application and measurements. [Contact: Francois D. Martzloff, (301) 975-2409]

\section{ADDITIONAL INFORMATION}

Lists of Publications

Gibson, K.A., Page, J.M., and Miller, C.K.S., A Bibliography of the NBS Electromagnetic Fields Division Publications, NBSIR 85- $: 040$ (February 1986).

This bibliography lists publications of the National Bureau of Standards' Electromagnetic Fields Division for the period from January 1984 through september 1985, with selected earlier publications from the Division's predecessor organizations.

[Contact: Kathryn A. Gibson, (303) 497-3132]

Kline, K.E., and DeWeese, M.E., Metrology for Electromagnetic Technology: A Bibliography of NBS Publications, NBSIR 86-3048 (June 1986).

This bibliography lists the publications of the personnel of the Electromagnetic Technology Division of NBS in the period from January 1970 through December 1985. A few earlier references that are directly related to the present work of the Division are included.

[Contact: Kathryn E. Kline, (303)

497-3678]

Palla, J.C., and Meiselman, B., Electrical and Electronic Metrology: A Bibliography of NBS Electrosystems Division Publications; NBS List of Publications 94 (January 1987).

This bibliography covers publications of the Electrosystems Division, Center for Electronics and Electrical Engineering, NBS, and of its predecessor sections for the period January 1963 to January 1987. A brief description of the Division's technical program is given in the introduction.

[Contact: Jenny C. Palla, (301)

975-2220]

Walters, E.J., Semiconductor Measurement Technology: A Bibliography of NBS Publications for the Years 1962-1986, NBSIR 87-3522 (February 1987). 


\section{Lists of Publications, cont'd.}

This bibliography contains reports of work performed at the National Bureau of Standards in the field of Semiconductor Measurement Technology in the period from 1962 through December 1986. An index by topic area and a list of authors are provided.

[Contact: E. Jane walters, (301)

975-2050]

\section{CEETE CALEMDAR}

September 14-16 (Research Triangle Park, NC)

VLSI and GaAs Packaging Workshop. This Workshop is co-sponsored by the Components, Hybrids, and Manufacturing Tecnnology society of IEEE and NBS; attendees are expected to be knowledgeable in the field and to participate in discussions. Topic areas include: VLSI and wafer scale package design (characterization and implementation, cost and performance driven solutions); package thermal design (characteristics, results, and issues); package interconnection options (wire bonding, TAB, flip nection options (wire bonding, TAB, flip chip, or optical); GaAs IC packaging (nigh speed packaging considerations); package electrical issues (reduction of parasitics and improvements in electrical performances); integrating package design (from die to system, including assembly and test issues); VLSI package materials advancements; die-attach solutions for large chips; new failure mechanisms in VLSI packaging. [Contact: George G. Harman, (301) 975-2097]

September 16-18 (Gai thersburg, MD)

Workshop on the Role of Optical Sensors in Power Systems' Voltage and Current Measurements. This Workshop is sponsored by NBS, the Bonneville Power Administration (BPA), the Electric Power Research Institute (EPRI), and the Empire State Electric Energy Research Corporation (ESEERC) and is intended for research and development engineers in utilities and in companies that supply equipment to the utility industry. The objective of this workshop is to identify anticipated opportunities for improved measurement techniques that should arise as power systems individually and collectively evolve to meet the needs of the 1990s. Presentations will stress the design and testing of optical systems for $60-\mathrm{Hz}$ voltage or current measurement; the interfacing of electronic or optical components with existing metering and control systems; opportunities for new measurement hardware resulting from increased automated control of power systems and of the testing of power system components; and optical techniques for the measurement of electric and magnetic fields in power systems or system components. The results of an NBS study evaluating optical techniques for power-system electrical measurements and carried out in agreement with BPA, EPRI, and ESEERC will be presented as an invited keynote. [Contact: Raymond S. Turgel, (301) 975-2420 or Robert E. Hebner, (301) 975-2403]

September 22-25 (Boulder, CO)

Noise Measurement Seminar. This fourday course is presented and hosted by the Electromagnetic Fields Division in cooperation with representatives from industry and the NBS Time and Frequency Division. It is intended for practicing noise metrologists and technical managers responsible for systems in which accurate measurements of thermal and phase noise are important. Attendees will learn the most important precautions to take in making accurate noise measurements and will receive a set of notes that are suitable for use in solving precision noise measurement problems. Course topics include reference thermal noise sources; thermal noise measuring systems and techniques; phase noise; and the problems of measuring thermal noise in passive components, amplifiers, and communication systems.

The course design combines formal lectures on theory presented by NBS staff 
1987 CEEE Calendar, cont'd.

and industry experts with demonstrations in NBS laboratories and demonstrations of commercial equipment. A special teature of the seminar is the opportunity each day for attendees to share their experiences in solving specific problems or their insights on practical noise measurement issues through short presentations to the assembled group. Time is scheduled for group discussions of these presentations and other topics raised by the seminar. [Contact: Sunchana Perera (303) 497-3546]

October 26-28 (Boulder, CO)

Symposium on Optical Materials for High Power Lasers (Nineteenth Boulder Damage symposium). This symposium is cosponsored by the National Bureau of Stanaaras, the American society for Testing and Materials, the Air Force Ofilce of Scientific Research, the office of Naval Research, and the Defense Advanced Research Projects Agency and constitutes a principal forum for the exchange of information on the physics and technology of materials for highpower lasers.

Topics to be aiscussed include new materials, bulk damage phenomena, surface and thin-iilm damage, design considerations for high-power systems, and fundamental mechanisms of laser-induced aamage. Proceedings of the symposium will be publisned (Note: The collection of Symposium proceedings contains information on optics for all aspects of high-power/high-energy lasers, including environmental degradation, durability, fabrication, material growth and deposition processes, and testing). [Contact: Susie A. Rivera (303) 497-5342]

December 10-11 (Gaithersburg, MD)

Power Semiconductor Devices Workshop. This workshop, sponsored jointly by IEEE and NBS, is intended to bring together for interactive participation those actively working in the field of power semiconductor devices. It will be held in conjunction with the 1987 IEEE International Electron Devices Meeting in Washington, DC. Four specific topic areas have been selected, based on the response to a questionnaire sent to over niques for the measurement of electric and magnetic fields in power systems or system components. The results of an NBS study evaluating optical techniques for power-system electrical measurements and carried out in agreement with BPA, EPRI, and ESEERC will be presented as an invited keynote. [Contact: Robert E. Hebner, (301) 975-2403]

\section{CERBs Calendar}

February 10-12 (San Diego, CA)

IEASE Semiconductor Thermal and Temperature Measurement symposium. This fourth annual SEMI-THERM symposium is sponsored by the Components, Hybrids, and Manufacturing technology society of IEEE in cooperation with NBS and constitutes an international forum for the presentation of new developments in, and applications relating to, generation and removal of heat within semiconductor devices and measurement of junction temperatures experienced in various applications and environments. Major SEMI-THERM topic areas include thermal measurements, thermal characterization, applications, and computation and software.

The program includes keynote speakers, technical presentations, tutorial sessions, workshops, and an exhibit. In addition, the semiconductor Equipment and Materials Institute has scheduled in conjunction with SEMI-THERM a meeting of its Thermal Measurements Task Force, to which attendees are invited. [Contact: Frank F. Dettinger, (301) 975-2054]

May 11-13 (Los Angeles, CA)

Intersociety Conference on Thermal Phenomena in Fabrication and Operation of Electronic Components. This conference is sponsored by the components, 
1988 CEEE Calendar, cont'd.

Hybrids, and Manufacturing Technology Society of the IEEE, in cooperation with ASME Committee $\mathrm{K}-16$ on Heat Transfer and NBS. It is intended to provide an interdisciplinary forum for exploring the progress made in understanding, analyzing, and modeling thermal transport processes and thermally induced fallures in the fabrication, assembly, and use of logic, memory, and datastorage systems. Major topic areas covered are 1) processing and fabrication, including state-of-the-art semiconductor crystal growing techniques; thermal stress in wafers, chips, substrates, PC boards, and joints; and encapsulant behavior with respect to solidification, outgassing, mechanical properties, and water vapor diffusion and absorption; 2) packaging technology, including means for cooling components from cryogenic to high temperatures and reliability as affected by failure mechanisms such as dopant migration and intermetallic growth; and 3) peripheral equipment, including data storage in both magnetic and optical media and thermal issues in dot-matrix and thermal printer heads. The conference is being held in conjunction with the Electronics Components Conference (May 9-11) at the same site. [Contact: Frank F. Dettinger, (301) 975-2054]

\section{Planned}

Early summer (Vail, CO)

Combined Short Course on Optical Fiber and Laser Measurements. [Contact: Aaron A. Sanders, (303) 497-5341]

Early fall (Boulder, CO)

Fiber Optics symposium. [Contact: Aaron A. Sanders, (303) 497-5341]
Late fall (Boulder, CO)

Symposium on Optical Materials for High Power Lasers (20th Boulder Damage Symposium). [Contact: Aaron A. sanders, (303) 497-5341]

\section{CEEAB SPONSORS}

National Bureau of Standards

Department of Defense

Defense Nuclear Agency; National

Security Agency; Combined

Army/Navy/Air Force Calibration

Coordination Group

U.S. Air Force

Hanscom Air Force Base; Newark Air

Force Station; Space \& Missile

Organization; Wright-Patterson Air

Force Base

U.S. Army

Fort Belvoir; Fort Monmouth; Harry Diamond Laboratories; Redstone

Arsenal

U.S. Navy

Naval Surface Weapons Center;

Weapons Support Center/Crane; Office

of Naval Research; Naval Air

Engineering Center

Department of Energy

Energy Systems Research; Fusion

Energy; High Energy \& Nuclear

Physics; Bonneville Power

Administration

Department of Justice

Law Enforcement Assistance

Administration

Department of Treasury

Bureau of Engraving and Printing

Department of Transportation

National Highway Traffic Safety

The Charles Stark Draper Laboratory

Sandia National Laboratories 
1. PUBLICATION OR REPORT NO.
2. Performing Organ. Report Nof 3

3. Publication Date

August 1987

4. TITLE AND SUBTITLE

Center for Electronics and Electrical Engineering Technical Publication Announcements Covering Center Programs, October-December 1986, with 1987 CEEE Events Calendar

5. AUTHOR(S)

E. Jane Walters, compiler

6. PERFORMING ORGANIZATION (If joint or other than NBS, see in structions)

7. Contracd Grant No.

\section{NATIONAL BUREAU OF STANDARDS U.S. DEPARTMENT OF COMMERCE GAITHERSBURG, MD 20899}

9. SPONSORING ORGANIZATION NAME AND COMPLETE ADDRESS (Street, City, State, ZIP)

U.S. Department of Commerce

National Bureau of Standards

National Engineering Laboratory

Center for Electronics and Electrical Engineering

10. SUPPLEMENTARY NOTES

All technical information included in this document has been previously approved for publication.

$\square$ Document describes a computer program; SF-185, FIPS Software Summary, is attached.

11. ABSTRACT (A 200-word or less foctual summary of most significant information. If document includes a significant bibliogrophy or literature survey. mention it here)

This is the eleventh issue of a quarterly publication providing information on the technical work of the National Bureau of Standards Center for Electronics and Electrical Engineering. This issue of the Center for Electronics and Electrical Engineering Technical Publication Announcements covers the fourth quarter of calendar year 1986. Abstracts are provided by technical area for papers published this quarter.

12. KEY WORDS (Six to iwelve entries: alphabetical order: copitalize only proper names; and separaze key words by semicolons) antennas; electrical engineering; electrical power; electromagnetic interference; electronics; instrumentation; laser; magnetics; microwave; optical fibers; semiconductors: superconductors

13. AVAILABILITY

X Unlimired

For Official Distribution. Do Not Release to NTIS

Order From Superintendent of Documents, U.S. Government Printing Office, Washington, D.C. 20402.

Xrder From National Technical Information Service (NTIS), Springfield, VA. 2216I
14. NO. OF PRINTED PAGES

15. Price 

OFTTCAAL BUSINESS

PENALTY FOR PRIVATE USE, $\$ 300$

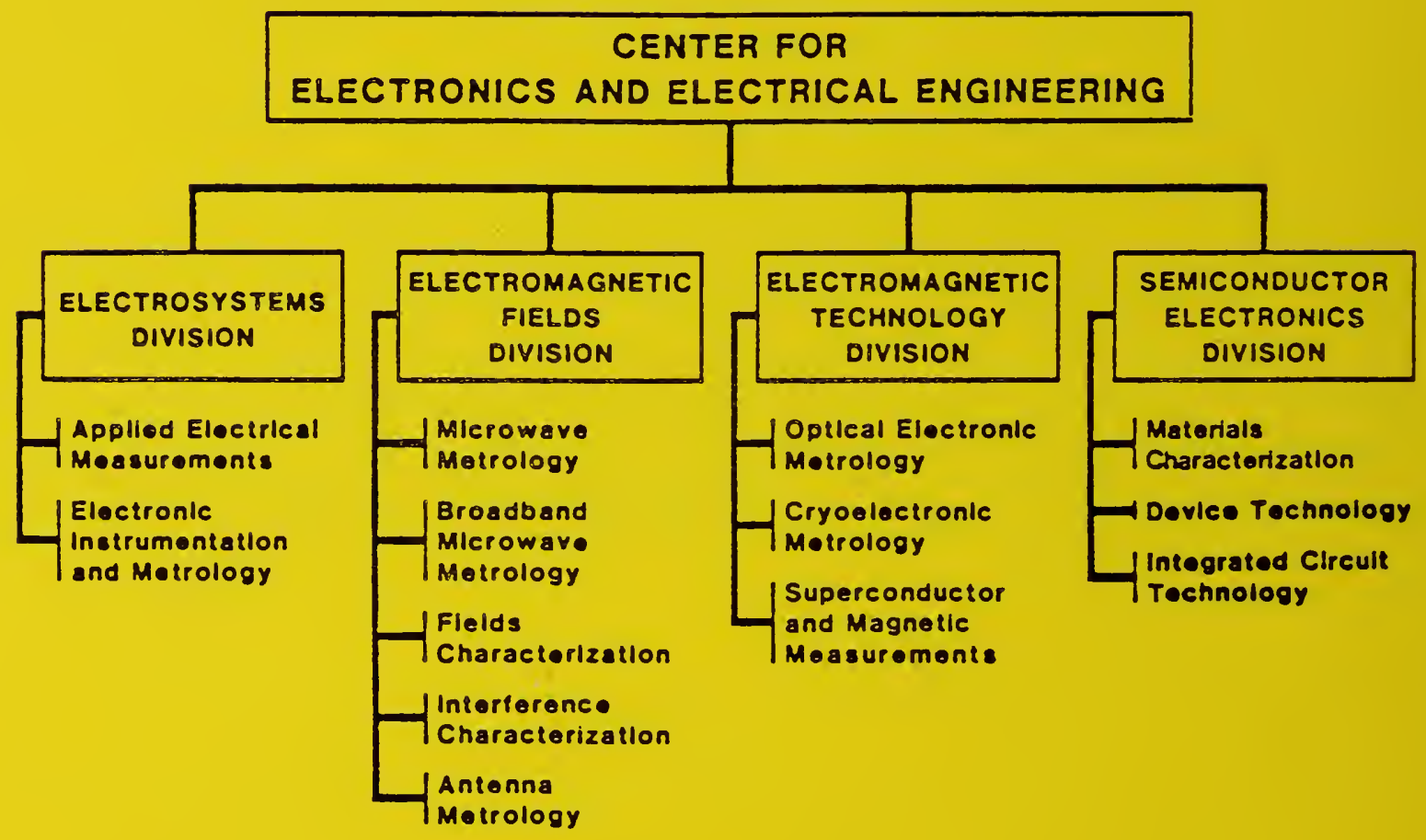

\section{KEY CONTACTS:}

Center Headquarters (720)

\section{Electrosystems Division (722)}

Electromagnetlc Fields Division (723)

Electromagnetlc Technology Division (724)

Semiconductor Electronics Division (727)

INFORMATION:

For additional Information on the Center for Electronics and Electrical Engineering, write or call:
Director, Mr. Judson C. French (301) 975-2220 Deputy Director, Mr. Robert I. Scace (301) 975-2220

Chlef, Dr. Oskars Petersons (301) 975-2400

Chlef, Dr. Ramon C. Baird (303) 497-3131 Chlef, Dr. Robert A. Kamper (303) 497-3535 Chlef, Mr. Frank F. Oettinger (301) 975-2054

Center for Electronics and Electrical Englneering

National Bureau of Standards

Metrology Bullding, Room B-358

Galthersburg, MD 20899

Telephone (301) 975-2220 